\title{
How to Improve Your Writing by Standing on Your Head
}

\author{
COMMUNICATION CORNER
}

\author{
by Philip Yaffe
}

\section{Editor's Introduction}

Each "Communication Corner" essay is self-contained; however, they build on each other. For best results, before reading this essay and doing the exercise, go to the first essay "How an Ugly Duckling Became a Swan," then read each succeeding essay. 


\title{
How to Improve Your Writing by Standing on Your Head
}

\author{
COMMUNICATION CORNER
}

\author{
by Philip Yaffe
}

You may not have thought about it, but newspapers provide the best examples of clear, concise, dense (factual) writing you can find anywhere. Otherwise people wouldn't read them. Journalists not only write well, they do so with extreme rapidness. When a news event occurs, they don't have the luxury of spending several days to put together their text. At best, they have a few hours.

Learning how journalists work their "daily miracles" can help you write better at your more leisurely pace.

Here is an article from an international newspaper.

Britain yesterday renewed its call for the United Nations to mount a peacekeeping operation in the violence-torn Darfur region of Sudan in response to increasing complaints from aid agencies on site that international efforts to help Darfur's desperate, displaced population are woefully inadequate.

At the same time, Her Majesty's Government is joining with other European Union countries to threaten sanctions against Sudan unless its government energetically moves to end the "ethnic cleansing" against black villagers in Darfur by the mainly Arab Janjaweed militias. U.N. officials report that the conflict has already claimed from 30,000 - 50,000 lives and about 1.2 million people have been displaced, with about 200,000 seeking refuge in neighboring Chad.

In the first paragraph, we learn:

1. The British Government is concerned about the situation in Darfur.

2. Darfur is a violence-torn region of Sudan.

3. Britain believes a peacekeeping force is urgently needed.

4. It is pressing the United Nations to supply this peacekeeping force.

5. This is not the first time Britain has called on the U.N. to supply a peacekeeping force.

6. The population of Darfur has been displaced. 
7. Aid agencies in Darfur say international assistance to these distressed people is inadequate.

In the second paragraph, we learn:

1. The trouble in Darfur is a race war.

2. Arab militias are attacking black villagers.

3. Britain and other European Union countries believe the Sudanese government is not doing enough to stop the war.

4. The threat of sanctions against Sudan is imminent, if its government does not quickly take action to end the attacks.

5. To date, some $30,000-50,000$ people have been killed.

6. About 1.2 million people have been displaced.

7. About 200,000 refugees have fled across the border into the neighboring country of Chad.

8. These figures come from the United Nations, which is a reliable source.

Imagine you had known absolutely nothing about Darfur before reading this text. Within two paragraphs you have learned virtually everything you need to know about this tragic situation. This is certainly clear, concise, dense writing at its best. ${ }^{1}$ Unfortunately, it is seldom recognized as such. According to the adage: Today a newspaper may be the most valuable thing in the world; tomorrow it is good only for wrapping fish.

Now that you appreciate the remarkable qualities of newspaper writing, the question is: How does it happen? And how can you apply its lessons to your type of writing?

\section{Turning Things on Their Head}

Journalists use an ingenious technique called the "inverted pyramid." Before seeing how it works, it would be useful to see where it came from.

A couple of centuries ago, poor literacy and primitive printing techniques meant newspapers had few readers, few pages, and were published infrequently (once a week or even once a month). As literacy and printing techniques improved, the number of readers increased, the number of pages increased, and so did frequency. Most newspapers were published at least once a week, some 2-3 times a week. Many even became dailies.

1 For a functional definition of clarity, conciseness, and density, see Communication Corner No. 2: "The Three Acid Tests of Persuasive Writing") 
This accelerating pace of production created a serious technical problem. In more leisurely days, if a story was too long for the space assigned to it, there was always plenty of time to either rewrite it or redesign the page. However when newspapers became dailies, this was no longer possible.

What newspapers needed were stories that could be cut off from the bottom. In this way, instead of laboring to revise a story at the last minute, editors could simply remove the last few sentences or paragraphs, and the job was done.

In order to do this, stories had to be written in a very special way. It is of no value simply to cut from the bottom if the lost information is crucial for the reader to understand what the story is all about. Consequently, stories had to be written "top down." All key information had to be concentrated at the beginning and all secondary information presented in declining order of importance. In this way, text could be deleted from the bottom and no one would know that it had ever been there.

This story structure became known as the "inverted pyramid." It worked extremely well because it not only solved the mechanical problem of overly long texts, it also turned out to be how people prefer to get their information, particularly when they are in a hurry.

With today's computer technology, the mechanical problem that gave rise to the inverted pyramid is no longer relevant. However, because it constitutes the very basis of good expository writing, the inverted pyramid is still held in high esteem.

Imagine an upside-down pyramid, or rather a triangle, with its point at the bottom and the wide part at the top. The top, where all the key information is concentrated, is called the "lead." The second part, which contains the secondary information (details), is called the "body."

\section{How to Construct the Lead}

The beginning of the story ("lead") must be clear and concise. This may be a single sentence or several sentences, whatever is necessary to give the reader a quick overview of what the story contains.

Journalists often say they spend about 50 percent of their time writing the lead of a story; writing the rest of the story also takes about 50 percent. Why? Because this is usually how long it requires them to determine the key information to put into the lead, and then to package it in a clear, concise manner. After that, the rest of the story almost writes itself.

Determining this key information is not a matter of intuition. There is a method. Before journalists start to write, they ask themselves a series of questions known as the " $5 \mathrm{Ws} \& \mathrm{H}$. " 
1. Who? Who are the person or persons involved in the story?

2. What? What happened?

3. When? When did it happen?

4. Where? Where did it happen?

5. Why? Why did it happen?

6. How? How did it happen?

Not all these questions will be relevant all the time, but they provide a good test. After writing the lead, check to see how many of the questions have been answered. If any answers are missing, there are two possible reasons:

- The question is relevant but was neglected, so rewrite.

- The question isn't relevant, so do nothing.

Another way to evaluate the lead is the "Stop Reading Test." Remember, you are generally writing for busy people. They generally do not want-and often do not need-to read the entire text. So ask yourself: At what point could someone stop reading and still get a clear, sharp picture of what the text is all about? If they would need to read most or all of the text, you must do some serious rewriting.

\section{How to Construct the Body}

The inverted pyramid is a pyramid because at each point from the lead downward the information becomes less and less important. This does not mean the information is necessarily less interesting; that is for each individual reader to determine. However, it is no longer vital.

But how do you arrange information in descending order of importance? Remember, it must be possible to delete information from the bottom without anyone knowing that it was ever even there.

This is certainly not easy; it requires a lot of skill and practice. But once again, there is a method that offers considerable help. It is called the " $Q$ \& A Technique." It works like this:

- After each sentence you write, examine it to see what question it could raise in the mind of your readers.

- Then answer it!

If you do this consistently, you will find the answers becoming more and more detailed, so the information will become less and less vital. When you run out of questions, it is probably a good time to stop writing. 


\section{A Pertinent Example}

Here is the lead of a story in an international newspaper.

Super-sportsman Lance Armstrong, seven-time Tour de France winner, filed suit Wednesday in a Paris court to force the publisher La Martinière to include his denial of doping charges in a new book about him, scheduled to reach bookstores in September.

Here are the $5 \mathrm{Ws} \& \mathrm{H}$.

1. Who? Lance Armstrong, seven-time Tour de France winner

2. What? Filed suit against the publisher La Martinière

3. When? Wednesday

4. Where? In a Paris court

5. Why? To include his denial of doping charges in a new book about him

6. How? (Not relevant)

Note the "who" is not simply Lance Armstrong, but "Lance Armstrong, seven-time Tour de France winner." The name Lance Armstrong may not be immediately familiar to everyone, but with this description, even people who have never heard of him would now know who he is.

Similarly, the "what" is not simply that he filed a lawsuit but that he filed suit against "the publisher La Martinière." Most readers probably will not know who La Martinière is, but they will recognize the writer does, which reinforces their confidence in the accuracy of the text. Gaining reader confidence is essential to effective expository writing, and inserting precise detail wherever relevant is an excellent way to do it.

Starting from this lead, the story continues down the inverted pyramid. At each point the information becomes less vital, giving the reader the option to decide at which point they have read enough and can turn their attention to something else.

\section{How to Use the Inverted Pyramid in Your Type of Writing}

You may now feel that the inverted pyramid is an excellent idea-for newspapers. But is it relevant for the type of writing that you do?

Emphatically, yes! Remember, the inverted pyramid provides information in exactly the way people prefer it, particularly when readers are in a hurry.

Suppose you are writing some kind of company report-a financial analysis, a new product proposal, changes to the company's employment policies, etc. It runs to 20 pages. Obviously you can't organize it into one big inverted pyramid; even the most accomplished professional 
writer wouldn't attempt such a daunting feat. However, you can organize it into sections and subsections, and write these as inverted pyramids.

You can even go a step further. Most such reports begin with an executive summary. Write this as you would the lead of an inverted pyramid, i.e. be certain that all the key information is located in the executive summary and is presented in a clear, concise, confidence-building manner.

Contrary to conventional wisdom, you should write the executive summary before you write the body, at least as a rough draft. To emphasize the point, perhaps we should replace the term "executive summary," which implies writing the body first and then summarizing it, for something more appropriate such as "executive briefing," "executive focus," etc.

Treating the executive summary as the lead of an inverted pyramid is not easy, but it confers some extraordinary advantages on both the writer and the readers.

\section{Advantages for the Writer}

With an executive summary written like the lead of an inverted pyramid, you can:

1. Determine what information you really need in the body of the report (key importance, secondary importance), and what can be eliminated (no importance).

2. Organize the body into the most appropriate sections and subsection.

3. Present the information in each section and subsection in descending order of importance.

\section{Advantages for the Reader}

With an executive summary written like the lead of an inverted pyramid, readers can:

1. Get a clear overview of what the report contains.

2. Determine which sections and subsections of the body may be of particular interest.

3. Decide whether or not they even need to read the body at all.

Remember, you are dealing with busy people; they have neither the time nor the desire to read the entire report. What they really want is for the writer to clearly identify what they must read. Any additional material they may wish to read should be left to their own judgment.

The general structure of a well-written report would thus consist of two parts: 
1. Executive Summary: Written like the lead of an inverted pyramid, i.e. build it on the 5 Ws \& $H$.

2. Body: Written in sections and subsections, each one in the form of an inverted pyramid.

I recently had a discussion about the ideas in this essay with a journalist friend of mine, who is the president of a major news distribution company. He suddenly realized over his 40-year career, the inverted pyramid had become so much a part of him that he unconsciously uses it in virtually everything he writes: letters, emails, reports, financial statements, new product proposals, etc.

You will probably never reach the stage of using the inverted pyramid without a second thought. However, if you begin consciously using it as a first thought, I am certain you will be pleased at just how much it will help you write more clearly, concisely, and rapidly.

\section{HOMEWORK: Retrospective to Communication Corner No. 2}

In the previous "Communication Corner," I showed you a commented text and asked you to try to apply the three acid tests of persuasive writing to produce something better. Before going on to a new homework assignment based on the three acid tests and the inverted pyramid, below is how the text from last time might have been revised. Remember: While it is always necessary to apply the three acid tests, the inverted pyramid, and other techniques, different writers will use them use them differently, so good text can be written in many different ways. This is only one example.

[Commented Text; comments are in italics]

\section{"Animal Production, Good or Bad?"}

The title is banal. Try something that better intrigues the imagination, such as:

- How much longer can we afford "cheap" food?

- Cheap food: the sticker price doesn't even begin to tell the cost

- Is cheap food pricing the planet out of existence?

Animal production for human exploitation adversely impacts our environment, and our lives.

This is a startling statement that needs some explanation before passing on to the historical perspective on animal production. Add some information here that gives the reader a better idea of the scope of the problem. 
Animals have been farmed for human use for thousands of years. But the middle of the $20^{\text {th }}$ century saw the beginning of a significant change in animal farming. New technologies allowed for high density farming while economies demanded it. This hightech, high-volume farming has commonly been referred to as factory farming, but in more sophisticated circles CAFO (Concentrated Animal Feed Operation) is probably preferred. The nature of this mode of farming improved efficiency, lowering the unit cost of bringing animal products to the grocery shelves. But, it also created and accelerated inherent problems in the animal production industry.

The food animal business; meat, dairy and egg, provides products highly demanded by the majority of the population. It also supplies jobs for a significant segment of society and financial gratification for those in position to benefit. This industry has grown as a result of demand and the ability to supply that demand with modern tools and technologies. Along with the growth of the animal production industry came a growth in concern for the impact this industry has on the environment and ultimately-life. As with many industries the true cost of animal products are not evident in the sticker price. The deferred costs, not paid at the time of purchase, get paid eventually. These costs include: destruction of the environment, sickness, disease, and early death.

This statement cries out for some kind of explanation. People might intuitively accept that factory farming is not "natural" and therefore probably has a negative impact on the environment. But what do you mean that it also leads to illness, disease, and early death? You talk about this later on in terms of cancer and vascular disease. However, without some clue as to what you are talking about, I am already disinclined to read any further.

Our children and grandchildren will continue to pay for our shortsightedness. Another, less tangible, by-product of this industry is psychological stress. This stress affects the suppliers as well as the consumers-in as much as slavery adversely affected the slave owner as well as the slave.

Now I am certain I would stop reading. Comparing animal production to human slavery just seems too outlandish to be serious. You could perhaps develop this idea later on (much later on), but putting it here as a throwaway line is almost certain to alienate the majority of your potential readers. 
[Revised Text]

\section{“How Much Longer Can We Afford 'Cheap Food'?”}

Animal production for human exploitation adversely impacts our environment and our lives.

This declaration should raise no eyebrows today, whereas fifty to a hundred years ago it probably would have been considered absurd. Over the past century, and particular over the past half century, we have become increasingly aware that the sticker price doesn't even begin to tell the true cost, not just of food but virtually everything else we buy because of short, medium, and particularly long-term environmental and social costs of producing them. Food, however, holds a particularly important place in the human psyche. Everyone needs it, everyone desires it, and everyone wants it at the lowest possible price. But as just noted above, the price you pay and the actual cost are two different things.

Let's consider the case of animal farming.

Animals have been raised for human use for thousands of years. However, the middle of the 20th century saw the beginning of a significant change. New technologies allowed for high-density animal farming. This high-tech, high-volume farming is commonly been referred to as factory farming; however, in more sophisticated circles the preferred term is CAFO (Concentrated Animal Feed Operation). Application of this mode of farming significantly improved efficiency, lowering the unit cost of bringing animal products to supermarket shelves. But it also created and accelerated inherent problems in the animal farming industry.

The animals for food business (meat, dairy, eggs) provide products in high demanded by the majority of the population. It also creates jobs for a significant segment of society and financial rewards for those in position to benefit. The industry has grown due to constantly rising demand and the ability to supply that demand with modern tools and technologies. As with many industries, the true cost of animal products are not evident in the sticker price. The deferred costs, not paid at the time of purchase, must get paid eventually, probably by our children, but most certainly by our grandchildren.

Here I will make a startling statement, which the remainder of this paper will explore and defend. These downstream costs not only include environmental degradation (as might have been expected), but also illness, disease-and even premature death. 


\section{Current Homework}

Here is an example of the difference paying attention to the $5 \mathrm{Ws} \& \mathrm{H}$ in the lead of an article (who, what, when, were, why, how) can make in grabbing and holding the reader's attention. After reading the example, you will be asked to revise another article in the same way.

[Here is how the article might look if written without due attention to the 5 Ws \& H.]

\section{"Drug Delays Alzheimer's Onset by Six Months"}

People with mild but measurable memory problems who took the drug donepezil, trademarked Aricep, delayed the onset of Alzheimer's disease by an average of a half year, a study has shown.

The research indicates that the drug works for just a short time and then stops. Still, the report is the first to find a drug therapy that delays the onset of Alzheimer's in people at high risk of the disease.

The result does not directly take researchers closer to a cure for Alzheimer's, but understanding how the drug prevents the disease's onset could provide some important clues.

[Here is how the article actually looked when written by a professional conscientiously applying the 5 Ws \& H.)]

\section{"For the First Time a Drug Shown to Delay Onset of Alzheimer's Disease"}

Donepezil, trademarked Aricep, has been shown to delay the onset of Alzheimer's disease in people at high risk. This is the first time any drug therapy has ever demonstrated such an effect.

A clinical study reported that the drug delayed onset of Alzheimer's by an average of six months in people with mild but measurable memory problems, a strong risk factor for the mind-destroying disease.

Six months of course is not very long. However, the fact that the drug worked at all is already a breakthrough, because it could provide important clues towards better prevention, treatment, and even a cure.

\section{Exercise Specifications}

Now it's your turn. Here is how an article might look if written without due attention to the $5 \mathrm{Ws} \& \mathrm{H}$. Apply the principles of the inverted pyramid and the $5 \mathrm{Ws} \& \mathrm{H}$ to make it more attention grabbing. If you feel that some crucial information is missing, research it or make it 
up. If you feel there is information that does not belong in the lead of the article but farther down, leave it out.

\title{
"Radical Proposal to Defeat Motor Neuron Disease"
}

The scientist who created Dolly the sheep yesterday applied for a license to clone human embryos to find a cure for motor neurone disease. Professor lan Wilmot plans to use the controversial procedure to study the devastating condition that has afflicted Professor Steven Hawking, actor David Niven, and former England football manager Don Revie. Motor neurone disease affects about 5,000 patients in Britain, most of whom die within two to five years after diagnosis.

\begin{abstract}
About the Author
Philip Yaffe was born in Boston, Massachusetts, in 1942 and grew up in Los Angeles, where he graduated from the University of California with a degree in mathematics and physics. In his senior year, he was also editor-in-chief of the Daily Bruin, UCLA's daily student newspaper. He has more than 40 years of experience in journalism and international marketing communication. At various points in his career, he has been a teacher of journalism, a reporter/feature writer with The Wall Street Journal, an account executive with a major international press relations agency, European marketing communication director with two major international companies, and a founding partner of a specialized marketing communication agency in Brussels, Belgium, where he has lived since 1974 . He is the author of more than 20 books, which can be found easily in Amazon Kindle.
\end{abstract}

DOI: $10.1145 / 3105919$ 